\title{
LOGISTICS AUDIT IN A TRANSPORT COMPANY
}

\begin{abstract}
Logistics audit is an effective tool of logistics management of a company, which serves to analyze and control the efficient and economic implementation of logistics activities. Today, more and more companies apply logistics audit in their practice, because it appears to be a very effective tool in today's turbulent business environment. Such a tool assesses the state and performance of the management of the company's logistics activities. The logistics audit determines changes and settings of individual processes that will lead to an increase in the quality and performance of the logistics system as a whole. Which means increasing the competitiveness of the company. The article focuses specifically on the application of logistics audit within the transport company. Because so far this tool has been applied mainly in the conditions of manufacturing companies and focused on optimizing the logistics of production processes. The article describes the procedure of performing a logistics audit and analyzes the main processes in a transport company.
\end{abstract}

Keywords: logistics, audit, logistics system, logistics audit methodology, process

Ekaterina Zmeškal ${ }^{1}$

${ }^{1}$ Faculty of Operation and Economics of Transport and Communications University of Žilina, Univerzitná 8215/1, 01026 Žilina; +421/41 513 3434; ekaterina.blinova@fpedas.uniza.sk

Jozef Majerčák ${ }^{2}$

${ }^{2}$ Faculty of Operation and Economics of Transport and Communications University of Žilina, Univerzitná 8215/1, 01026 Žilina; +421/41 513 3410; jozef.majercak@fpedas.uniza.sk

Adrián Šperka ${ }^{3}$

${ }^{3}$ Faculty of Operation and Economics of Transport and Communications University of Žilina, Univerzitná 8215/1, 01026 Žilina; +421/41 513 3434; adrian.sperka@fpedas.uniza.sk

\section{Introduction}

More and more companies are using logistics audit services, because in today's competition, details really matter. This type of audit provides an opportunity for a company to plan and reorganize its operations so that nothing is left to accident. The logistics audit is responsible for assessing the state and performance of management with regard to the set of logistics activities defined by the department. It also has the task of determining such changes and settings that will lead to an increase in the quality and performance of the logistics system and thus to an increase in the competitiveness of the company. The basic goals of a logistics audit can to be specified according to the specific logistics needs of the company. The scope of the audit, of course, depends on the size of the entity concerned, its product and process activities. During the implementation, it is necessary to pay attention to the precise preparation and organization of the audit.

Within the Slovak Republic, the Chamber of Logistics Auditors associates logistics auditors, promotes their interests and guarantees the professional level of logistics audits. For the professionalization of logistics services in the Slovak Republic, professional meetings of logistics are organized every year.

The logistic audit is:

- standardized analytical and project process, which is focused on the logistical functions of the corporate management system;

- $\quad$ is a standardized analytical procedure with its own methods, defined content, procedures, goals and outputs. It focuses on the primary functions of the company (purchase, production, sales) and analyzes them from the perspective of material and information flow. (Chamber of logistics auditors)

A logistics audit is not just a statement of the state of a company's logistics performance, it provides procedures and instructions on how the situation can change to the desired state. He answers the questions "what needs to be changed?" "How to change it", "who will make the changes" and "how much will it cost". The purpose of the logistics audit is to diagnose the state of the logistics system in the company and define a program to increase its productivity. The project nature of this program allows for the implementation of immediate organizational interventions leading to rapid effects, as well as fundamental conceptual changes in logistics processes.

The basic principles of the logistics audit are its methodological structure (results when repeating the audit may be comparable), objectivity and independence of the auditor, confidentiality of business data, controllability of inputs. The audit monitors both quantitative (measurable parameters that characterize the investigated logistics processes by numerical value) and qualitative indicators (subjectively evaluated parameters such as staff qualifications, level of communication between departments).

\section{Logistics audit procedure}

In general, the logistics audit is performed in the following steps: 
1. Presentation of the logistics audit methodology according to which it will be performed.

2. Preparation of a logistics audit - the interview itself and measurement within the company. In this step, the auditor identifies what are the main and supporting processes in the company, which processes contribute most to the fulfillment of the company's mission.

3. Setting audit objectives - based on the set objectives, it is decided whether the subject of the audit will be the entire logistics chain or only a specific part of it (selected logistics processes).

4. Audit processing. In this step, it is necessary to identify all relevant processes in the company, describe their running, or compile a process map. This step consists of two phases.

The first is an analysis of the current state of the company. Here, all relevant information is gathered on the basis of the selected objectives in order to examine the factors that influence the achievement of the set priorities. In this phase, the auditor creates an objective picture of material, financial and information flows, their interrelationships, through observation, communication with employees and the company's management.

- $\quad$ The second phase is the evaluation of the current situation. Based on the set qualitative and quantitative indicators, the auditor processes and evaluates the obtained data.

5. Processing of results and evaluation of relevant documentation - evaluation of collected data, proposal of measures, recommendations and verification of conclusions.

6. Presentation of results - internal discussion, formulation of assignments for the project of logistic changes. The auditor proposes a measure to eliminate "bottlenecks" and may prescribe to the company activities for their application in the company. The activities will then be carried out according to priorities (necessary, moderately urgent and recommended activities).

All audit conclusions are contained in the logistics audit report and three paragraphs are formulated for each area examined:

1. Statement of the current state of the area.

2. Assessment of the state and potential of the area.

3. Proposal of changes that will lead to the realization of the potential.

Within the project of logistic changes, the purpose and goals of the program, specification of activities and changes, including their prioritization, determination of the scope and ongoing evaluation time, organizational and technical support, schedule and budget with a forecast of economic return are always formulated. (Chamber of logistics auditors)

\section{Logistics system}

Logistic processes are included in all technological, production and economic activities of human action.
Therefore, it is appropriate to identify and investigate these processes, as their management and optimization can reduce economic costs without reducing product quality. Logistics is understood as a scientific field, which is characterized by a systems approach. Which means that the individual elements that the system contains and the links between them are examined. In the case of the logistics system, the elements and links are given by activities and processes associated with the material, respectively intangible flow from the source (production, extraction) to the point of consumption. It is a flow of material (or services), finances and information that together form a whole and interact with each other.

The main essence of the logistics system is the relationship between the manufacturer and the customer. In terms of material flow, it is transport and storage from the place of production to the customer. This means that the goods must almost always be removed from storage, loaded onto a means of transport and transported to the customer via the transport network, where they are usually unloaded from the means of transport and stored in a warehouse or they travel directly to production.

\section{Process approach in a transport company}

The key basis for the implementation of a logistics audit in every company is the examination of processes and the compilation of process maps. Because a uniform description of processes leads to their successful optimization and increased system performance. In-house processes should be a tool to fulfill the vision and goals of the business. They must follow each other, and every process must have meaning. Therefore, setting process goals and measurable indicators is very important. We need to know what the process should be aimed at and monitor how the process fulfills the goal (measure the result). Furthermore, it is essential to monitor whether the fulfillment of the process goal contributes to the overall fulfillment of the goals of the entire company. It follows that the definition of goals must begin at the level of the company's top management and gradually move to the lowest level in the form of sub-goals for individual processes. Therefore, in the third phase of the logistics audit - Setting goals, the strategic goals that the company wants to achieve by meeting the partial goals of the audit should also be proposed.

For a successful audit, it is necessary to identify the main processes in the company, which create value in the form of a product / service for the customer and are formed by a chain of benefit, which is a key area of the organization's business. The main processes therefore directly contribute to the fulfillment of the company's mission. (Pernica)

\subsection{The main processes of the transport company}

We will take a closer look at the example of a transport company focused on road transport, the company has its own means of transport and has a forwarding (sales) department - so it can resell some 
orders and thus use outsourcing of transport services of other companies. Then the main processes in the company can look like this (fir. 1):

Step 1.1: The customer orders shipping for a certain price and under certain conditions. The order can be made by phone, fax, email.

Step 1.2: The order proceeds for assessment by the sales department, which decides whether to accept the order (step 2.1) or not to accept it (step 2.0).

Step 2.1: On the part of the transport company, the sales department accepts the order and in the next step 2.2 it is decided whether to execute the order with its own means of transport or to use the services of another carrier. In the case of a new unverified customer, the sales department will request customer references from other companies. If the customer wants to verify the transport company, he can request references, check the Community authorization, CMR insurance, the allocation of the CEMT authorization, etc.

Step 2.3: The sales department decides that the order will be executed within the company and forwards it to the dispatcher. The dispatcher must choose the appropriate means of transport and the optimal route for the given transport. In the case of expensive goods, the customer (telephone or e-mail communication) must also approve the proposed means of transport and the route. In case the sales department decides to use the services of another carrier, steps 2.5 and 2.6 follow, the next steps 4.1 to 5.4 are similar to the steps 2.4 to 3.4 described below.

Step 2.4: After approving the means of transport and the route of transport, the dispatcher assigns the task to the driver, he sends to driver the transport itinerary (SMS-message, fax, email, communication on-board unit).

Step 3.1: The driver brings the vehicle to the place of loading, checks the loading and securing of the load, and receives the documents related to the transport (CMR consignment note - if it is an international transport, delivery note - if it is a national transport, or customs documents).

Step 3.2: Moving the load - the transport is performed by the driver. During transport, if necessary, the cargo can be cleared through customs (step 3.3), there are additional costs involved: CEMT authorization, international freight authorization, TIR carnet, certificate of origin, etc.

Step 3.4: When bringing the vehicle for unloading, the driver hands over copies of transport and customs documents to the customer and sends a notice to the dispatcher about the unloading of the goods. After the transport, the driver hands over the original documents to the economic department of the transport company. After processing the submitted documents, the economic department sends the confirmed original documents to the customer and issues an invoice for payment.

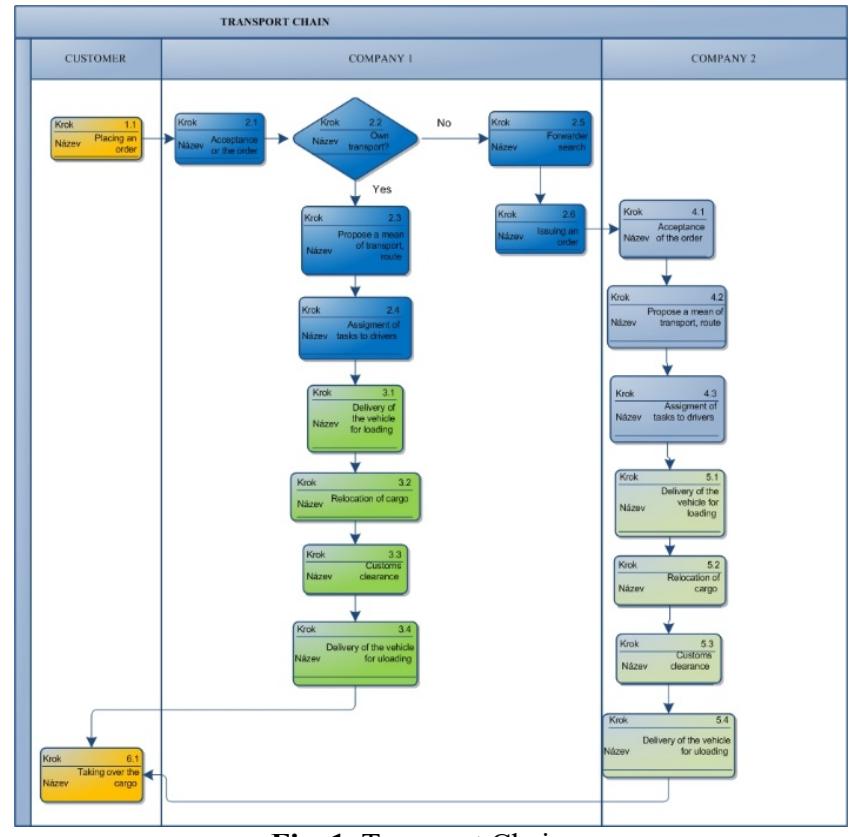

Fig. 1. Transport Chain

\subsection{Main process}

The main process in a transport company that brings profit and customer satisfaction is the actual transfer of cargo from place A to place B. Company A sells the goods to company $\mathrm{B}$ and company $\mathrm{C}$ arranges the transport from the starting point to the destination.

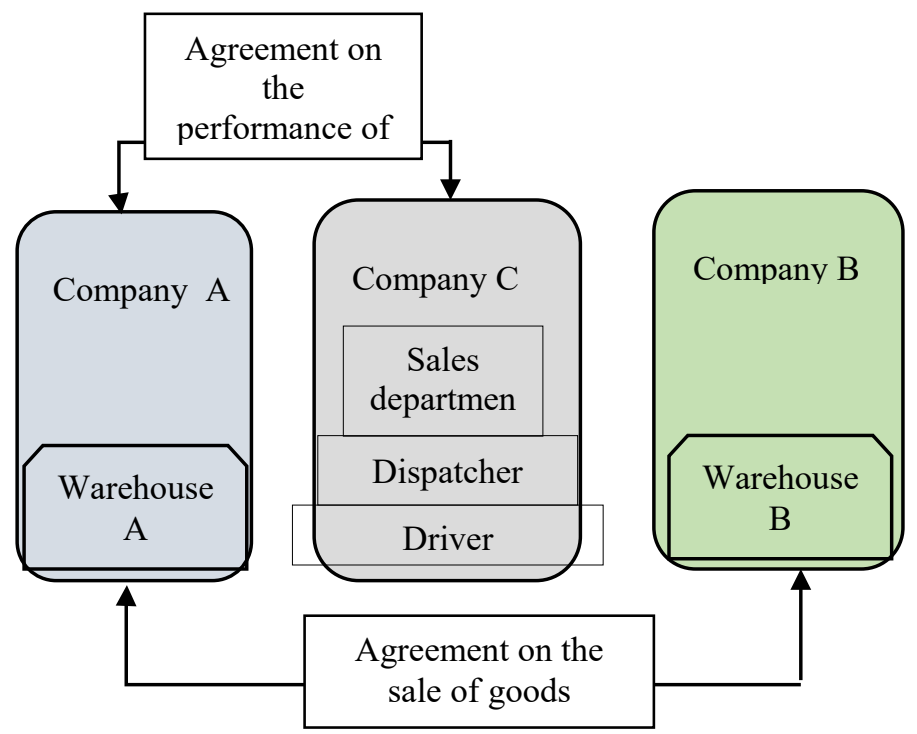

Fig. 2. Levels of management of logistics operations

From Figure 2 we see that the order concerns three levels of management in the company:

1. strategic level of management - agreement on the reason for transport between companies;

2. tactical level of control - the dispatcher processes the order and assigns tasks to the driver to bring the vehicle; 
3. operational level of management - the driver adapts his activity to the assigned tasks and the current traffic situation in the transport network.

This example shows why it is necessary to communicate with a number of company employees from different levels of company management in order to perform a successful logistics audit. Each employee has his or her own view of the process, determined by his or her position in the process hierarchy, with operational staff often seeing deeper into the process than the superior level of management, so to speak, at the epicentre. The role of the auditor is to examine the process as a whole and, based on the findings, to determine the optimal changes and settings of the process. power of process $=\frac{\text { benefit }}{\text { associated costs }}$

If the result of the ratio (1) is greater than 1 , it is a profitable process, otherwise it is a loss-making process. In such a situation, it is necessary to assess whether the process can be eliminated or whether optimization of the process and its costs is required.

Logistics audit makes extensive use of reengineering and process optimization techniques to simplify some activities while maintaining output quality and reducing costs where possible.

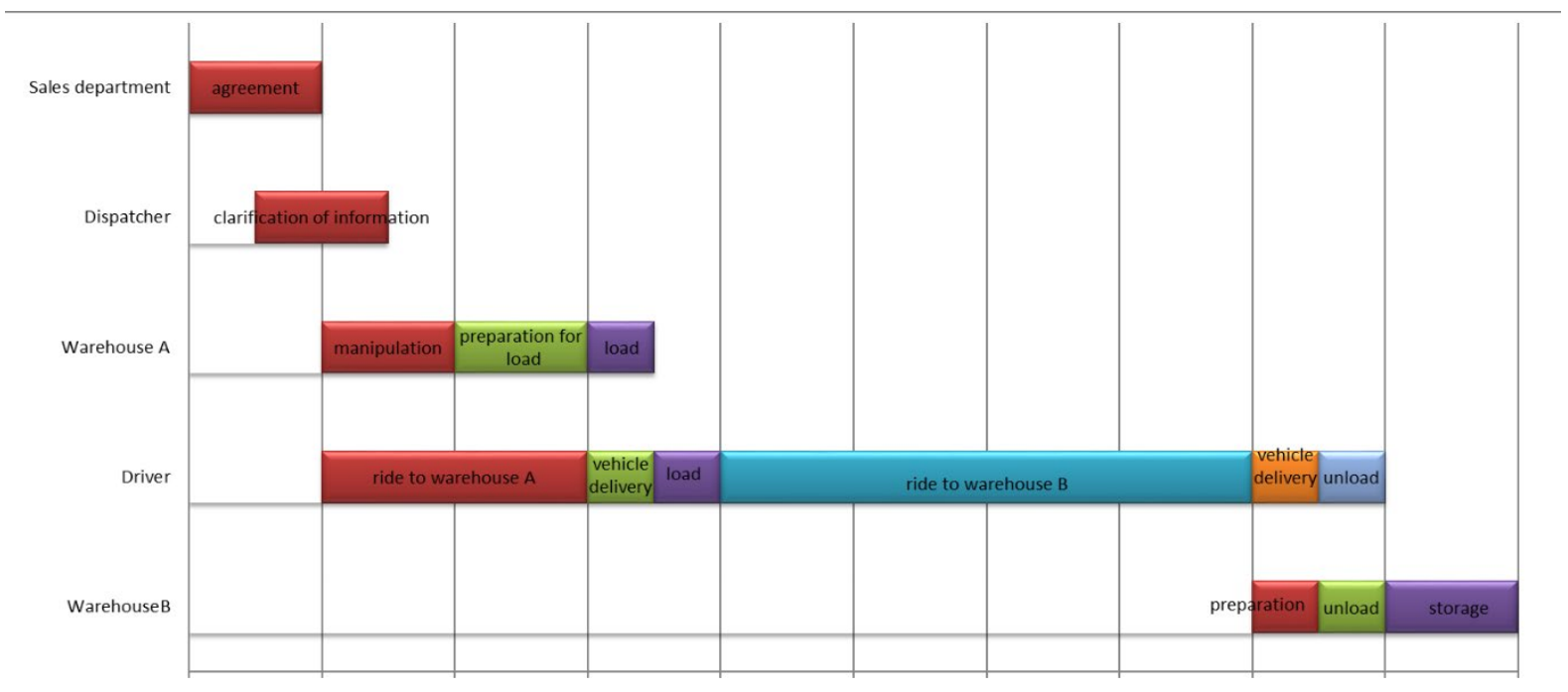

Fig. 3. Grantt diagram of order

When commissioning a transport, the time of its execution plays a big role, which in turn depends on the cooperation of individual subjects, the continuity of individual operations and other facts. The running of the order and the sequence of actions is shown in Figure 3 using a Grantt diagram.

As the most risky part of this process due to time and delay, we consider the transfer of a vehicle from the vehicle station to warehouse $\mathrm{A}$ and then to warehouse $\mathrm{B}$. This is due to the higher risk of unforeseen events within the public infrastructure. This delay can be avoided by means of optimal tracing and interactive control (sensing of road situations and subsequent information for the driver) or operative modification of the route and itinerary.

In this way, the auditor assesses each major process of the company and, based on the results, offers the company's management an overview of the current situation, possible bottlenecks and solutions.

The evaluation of processes is based on the assumption that the benefits provided by the main process outweigh the costs associated with the activities incurred to carry it out. We can write this relationship as follows:

\section{Conclusion}

For effective management of the logistics system, it is necessary to know this system well. In this case, the logistic audit appears to be a useful tool for getting to know the system in detail, locating bottlenecks in individual processes. In addition, it offers options for resolving the situation.

It is crucial for every business to benefit from its strengths and try to eliminate weaknesses. To do this, however, it is first necessary to name these strengths and then be able to use them effectively.

In the case of weaknesses, it is necessary to identify them, delimit them and offer a proposal for changes in order to improve or eliminate them. Logistics audit is an effective tool that can be used for these purposes.

\section{Acknowledgement}

The paper was supported by the project EUREKA E!11214 EPLOS - "European portal of logistics services" at Faculty of Operations and Economics of Transport and Communication, University of Žilina, Slovakia 


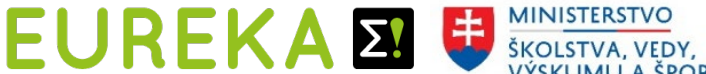 \\ innovation across borders SLOVENSKEJ REPUBLIKY}

\section{References}

Grasseová, M. 2008. Procesní řizení ve veřejnem sektoru. Brno: Computer Press, 2008.

Pernica, P. 2005. Logistika pro 21. Století (Supply Chain Management), 3 díl. Praha: RADIX,s.r.o., 2005. ISBN 80$86031-59-4$.

LOADO 2009: The International Journal of TRABSPORT\&LOGISTICS. Strakoš, V. 2009. 2009. Logistika a silniční doprava. 2009. ISSN 1451-107X.

TRANSBALTICA. Kudláč, S, Štefancová, V a Majerčák, J. 2017. Vilnius: s.n., 2017. Using the Saaty Method and the FMEA Method for Evaluation of Constraints in Logistics Chain.
TRANSCOM. Kudláč, S, Majerčák, J. and Mańkowski, C. 2017. 2017. The Proposal of Coordination the Rail and Bus Passenger Transport on the Relation Žilina Ružomberok.

Transport Means. Babon, M, Búda, M a Majerčák, J. 2012. Kaunas: s.n., 2012. Terminals for transportation of dangerous goods.

Transportation Reserch Precedia. Kudlac, S, Majercak, J a Majercak, P. Comparison of different variants of logistics chain with the use of air transport using the software application. Zv. Volume 28, s. 45 - 50.

2020 kla-sk.eu - Chamber of logistics auditors. Chamber of logistics auditors. [Online] [Cited: $14 \quad 04$ 2020.] http://kla-sk.eu/o-komore/.

Chamber of logistics auditors. [Online] Chamber of logistics auditors). [Date: $16.04 \quad 020$. http://www.kla.cz/cs/o-komore. 